\title{
Foot-and-mouth disease control in Zambia: A review of the current situation
}

\author{
Authors: \\ Yona Sinkala ${ }^{1}$ \\ D. Pfeiffer ${ }^{2}$ \\ C. Kasanga ${ }^{3}$ \\ J.B. Muma ${ }^{4}$ \\ M. Simuunza ${ }^{4}$ \\ A. Mweene ${ }^{4}$ \\ Affiliations: \\ ${ }^{1}$ Ministry of Livestock and \\ Fisheries Development, \\ Lusaka, Zambia
}

${ }^{2}$ Royal Veterinary College,

United Kingdom

${ }^{3}$ Sokoine University of

Agriculture, Tanzania

${ }^{4}$ School of Veterinary

Medicine, University of

Zambia, Zambia

Correspondence to:

Yona Sinkala

Email:

yona.sinkala@sacids.org

Postal address:

PO Box 30041, Lusaka,

Zambia

How to cite this abstract: Sinkala, Y., Pfeiffer, D., Kasanga, C., Muma, J.B., Simuunza, M. \& Mweene, A., 2012, 'Foot-and-mouth disease control in Zambia: A review of the current situation', Onderstepoort Journal of Veterinary Research 79(2), Art. \#472, 1 page. http://dx.doi. org/10.4102/ojvr.v79i2.472

Note:

Proceedings of the Conference of the Southern African Centre for Infectious Disease Surveillance 'One Health' held at the National Institute for Communicable Diseases, Johannesburg, July 2011

C) 2012. The Authors. Licensee: AOSIS OpenJournals. This work is licensed under the Creative Commons Attribution License.
Zambia has been experiencing low livestock productivity as well as trade restrictions owing to the occurrence of foot-and-mouth disease (FMD) and contagious bovine pleura pneumonia (CBPP). Foot-and-mouth disease was first recorded in Zambia in 1933 in the Western Province and since then the country has experienced repeated outbreaks. Bearing in mind the pressure that may be existing on the many risk factors for FMD including climate change, there is need to review our knowledge on FMD control.

We present the spatial distribution of the FMD outbreaks that have been recorded in Zambia in the last twenty years, and the effect of the vaccinations and movement control that have been applied. We propose further strain characterisation of previous FMD outbreaks, including full sequence of VP1 gene and the 5'UTR site. The data will be geo-coded and populated with risk factor attributes. We also present preliminary findings of the buffalo and cattle probang sampling that was conducted in Lochnivar and Kafue National Park. We further probang sampled 25 buffalo at each interface area in Sioma Ngwezi, Lukusuzi and Lower Zambezi national parks. Villages in close proximity to the buffalo populations as well as those not in close proximity will be multistage cluster sampled for comparison. The data will be geo-coded and populated with risk factor and foot-and-mouth disease virus (FMDV) characterisation attributes. Data collected using a pre-tested structured questionnaire will be geo-coded and populated with identified risk factors and stored in a database and will be spatially modelled to determine their effect on FMD occurrence and control measures. New outbreaks of FMD that may occur will be investigated to find out if there are new strains involved, species affected and predisposing risk factors.

The authors conclude that impacts of FMD on livelihoods if appropriate control measures are not put in place are far more devastating especially at community level. Presented with the current poverty levels failure to institute result oriented control measures will exacerbate the already lifethreatening situation. 